\title{
Comparison of Rehabilitation Outcomes with Acoustic Radiation Force (ARFI) Elastosonography in Hemiplegic Patients Treated with Neuromuscular Electrical Stimulation
}

\author{
Murat Toprak $^{1 *}$, Nurşen Toprak ${ }^{2}$ \\ ${ }^{1}$ Department of Physical Therapy and Rehabilitation, Medical Faculty of Van Yüzüncü Yıl University, Van, Turkey \\ ${ }^{2}$ Department of Radiology, Medical Faculty of Yüzüncü Yıl University, Van, Turkey \\ Email: *dr.murattoprak@gmail.com, nursentoprak31@gmail.com
}

How to cite this paper: Toprak, M. and Toprak, N. (2019) Comparison of Rehabilitation Outcomes with Acoustic Radiation Force (ARFI) Elastosonography in Hemiplegic Patients Treated with Neuromuscular Electrical Stimulation. Open Journal of Therapy and Rehabilitation, 7, 1-11.

https://doi.org/10.4236/ojtr.2019.71001

Received: December 24, 2018

Accepted: January 29, 2019

Published: February 1, 2019

Copyright $\odot 2019$ by author(s) and Scientific Research Publishing Inc. This work is licensed under the Creative Commons Attribution International License (CC BY 4.0).

http://creativecommons.org/licenses/by/4.0/

\begin{abstract}
To evaluate the gastrocnemius/soleus and biceps brachii muscle stiffness by Acoustic Radiation Force Impulse (ARFI) elastography in the hemiplegia patients, sixty patients with hemiplegia after stroke were recruited. Baseline data were collected including age, gender, body mass index, education level, dominant side, affected side, time since stroke, stroke etiology. All patients were evaluated with before treatment and posttreatment with Broonstroom staging, Modified Ashworth spasticity scale, and Functional Independence Measures scale. The patient was divided into 3 groups: 1) Neuromuscular electrical stimulation group, 2) Rehabilitation group, 3) Neurumusculer electrical stimulation + Rehabilitation group. Affected and unaffected side biceps and gastrocnemius, ARFI elastography measurements were used to measure thickness and elastic values. In addition, before and after treatment, length and thickness were measured from all patients. Of the 60 subjects, 28 were female (46.7\%) and $32(53.3 \%)$ were males, with an average age of $58.42 \pm 9.03$ years. There was a significant difference between the upper and lower limbs after the treatment in terms of Brunstroom staging. In terms of Modified Ashworth scale, there was a significant difference in lower extremity only after treatment. When compared to the affected/unaffected side, before and after treatment, there was a significant difference in the measurements in both the medial gastrocnemius and the lateral gastrocnemius in all three groups. Further research with larger numbers of patients for longer periods is needed to clarify the relationship between the muscle hardness and degree of spasticity.
\end{abstract}




\section{Keywords}

Hemiplegia, Rehabilitation, Acoustic Radiation Force İmpulse, Elastography, Electrical Stimulation

\section{Introduction}

Hemiplegia/hemiparesis is a common complication of stroke [1]. Hemiparesis, or muscular weakness of the upper and lower legs contralateral to the brain lesion, is the most frequent sign following a stroke or intracerebral hemorrhage [2]. In these patients, muscle weakness develops rapidly after stroke, contributing to reduced functional ability [3]. Following a stroke, a number of residual neurological- and functional limitations persist, including muscle weakness as a very common impairment. Restoring muscle strength is, therefore, a basic element in stroke rehabilitation [4].

In recent years, sonoelastography has been used to evaluate the skeletal muscles [5] [6] [7] [8]. There are several elastography techniques including sonoelastography, shear wave elastography, transient elastography, and acoustic radiation force elastography; each of which has a different type of stress application and method used to detect tissue displacement and construct the image [9]. Acoustic radiation force impulse (ARFI) strain imaging is an alternative approach for measuring strain. In this technique, a short-duration (0.1 - $0.5 \mathrm{~ms})$ high-intensity (spatial peak pulse average $=1400 \mathrm{~W} / \mathrm{cm}^{2}$, spatial peak temporal average $=0.7 \mathrm{~W} / \mathrm{cm}^{2}$ ) acoustic "pushing pulse" (acoustic radiation force) is used to displace tissue (displacement of $\sim 10-20 \mu \mathrm{m}$ ) in the normal direction, i.e. perpendicular to the surface. Thus, it is a less operator-dependent technique. In ARFI imaging, these speeds are given in $\mathrm{m} / \mathrm{s}$ [10]. ARFI imaging has been used to study a variety of tissues, including liver [11], breast [12], kidney [13], spleen [14], prostate [15], pancreas [16], testes [17], thyroid [18], and muscle and tendon [19]. There are few studies that ARFI elastography used in hemiplegic patients. Some earlier studies have measured SW speed in muscles such as the biceps brachii [20] [21] [22], vastus lateralis muscles [22] and gastrocnemius [22] [23] in flexor digitorum superficialis/flexor digitorum profundus [24], both healthy individuals and in individuals with neuromuscular dysfunction such as spasticity [25] [26] [27] [28].

By the use of this technique, the study proposed two principal objectives: firstly, the evaluation of the gastrocnemius/soleus and biceps brachii muscle stiffness in the hemiplegia patients and, secondly, to evaluate using ARFI the relationship between spasticity in the upper and lower extremities.

\section{Methods}

\subsection{Subjects and Study Design}

Sixty patients ( $32 \mathrm{M}$ and $28 \mathrm{~F}$ ) with hemiplegia after stroke were recruited the 
clinic of the department of physical therapy/rehabilitation medicine at our university medical center, between May and July 2017. Prior to admission, the patients were informed of its purpose and a written informed consent was obtained from each participant.

The criteria for inclusion in the study were 1) hemorrhagic or ischemic stroke 2) aged 18 - 85 years, 3) stroke duration 0 - 6 mounth, 4) have no aphasia or cognitive dysfunction. Patients who had any of the followings were excluded; heart failure, embolism/ thrombosis, history of trauma/surgery, infectious, unregulated diabetes mellitus, psychiatric disorders, stroke over 6 months, a history of botulinum toxin or neurolytic agents (phenol, alcohol) injection within 6 months, any other muscular/neurological disorders, refusal to participate in the study.

The study protocol was approved by the Ethics Committee of the OO University Hospital (B.30.2.YYU.0.01.00.00/99). The study was conducted in accordance with the principles of the Declaration of Helsinki.

\subsection{Clinical Evaluation}

Baseline data were collected including age, gender, body mass index, education level, dominant side, affected side, time since stroke, stroke etiology. All patients were evaluated with before treatment and posttreatment with Broonstroom staging, Modified Ashworth spasticity scale, and Functional Independence Measures scale.

Brunstroom staging was used to assess the motor development of hemiplegic patients. In this test, the healing process of the hemiplegic patient is defined as 6 stages. According to this staging, the lowest stage is stage I (flask, phase in which there is no voluntary movement), the highest stage was determined as stage VI (the stage of isolated joint movement).

Spasticity was assessed by Modified Ashworth Scale. Patients are evaluated on 5 points: 0 muscle tone is not increased and 4 is rigid in the direction of flexion and extension of the extremity.

Functional Independent Measurement (FIM); self-care was assessed to assess hand related functional disability. The FIM consists of 18 items that assess self-care, sphincter control, mobility, displacement, communication, and social perception functions. Each item is scored between 1 and 7. Total score 18 - 126 (fully dependent-fully independent). Adaptation of Functional Independence Scale to Turkish population, validity and reliability studies [29].

\subsection{Rehabilitation Program}

The patient was divided into 3 groups:

1) Neuromuscular electrical stimulation group (NMES): Neuromuscular electrical stimulation was applied on the biceps and gastrocnemius muscles of the paretic side, for 30 minutes daily, 5 days a week, for a period of 4 weeks.

2) Rehabilitation group: Brunstroom exercise was applied all extremities by a 
trained physical therapist, for 30 minutes daily, 5 days a week, for a period of 4 weeks.

3) NMES + Rehabilitation group: electro-stimulation + exercises were applied together, for 30 minutes daily, 5 days a week, for a period of 4 weeks (Figure 1).

\subsection{Ultrasound and ARFI Elastographic Technique}

We used a Siemens ultrasound machine with an ARFI based elastography option of Virtual Touch IQ technology (Siemens ACUSON S2000" care, Erlangen, Germany). US elastographic images of the study subjects' biceps muscles and gastrocnemius muscles (medial and lateral side) were obtained by a linear probe with $4-9 \mathrm{MHz}$ frequency bandwidt (9L4 Transducer, Siemens Healthcare, Erlangen, Germany). All ultrasound measurements, before and after treatment were performed by the same radiologist who had 9 years of experience and who was blind to the patients. First of all the subjects were taken in a supine position on an examination platform and the biceps were measured. Then the subjects were turned to the prone position and the GCM was measured both medially and laterally. Affected and unaffected side biceps and gastrocnemius, ARFI elastography measurements were used to measure thickness and elastic values. In addition, before and after treatment, $\mathrm{mm}$ length and thickness were measured from all patients.

\section{Statistical Analysis}

Statistical analysis was performed using the Statistical Package for the Social Sciences software version 16.0 software (SPSS Inc., Chicago, IL, USA). Descriptive data were expressed in mean \pm standard deviation, median, minimum-maximum and $\mathrm{n}(\%)$. The Student's t-test and Mann-Whitney $\mathrm{U}$ tests were performed to

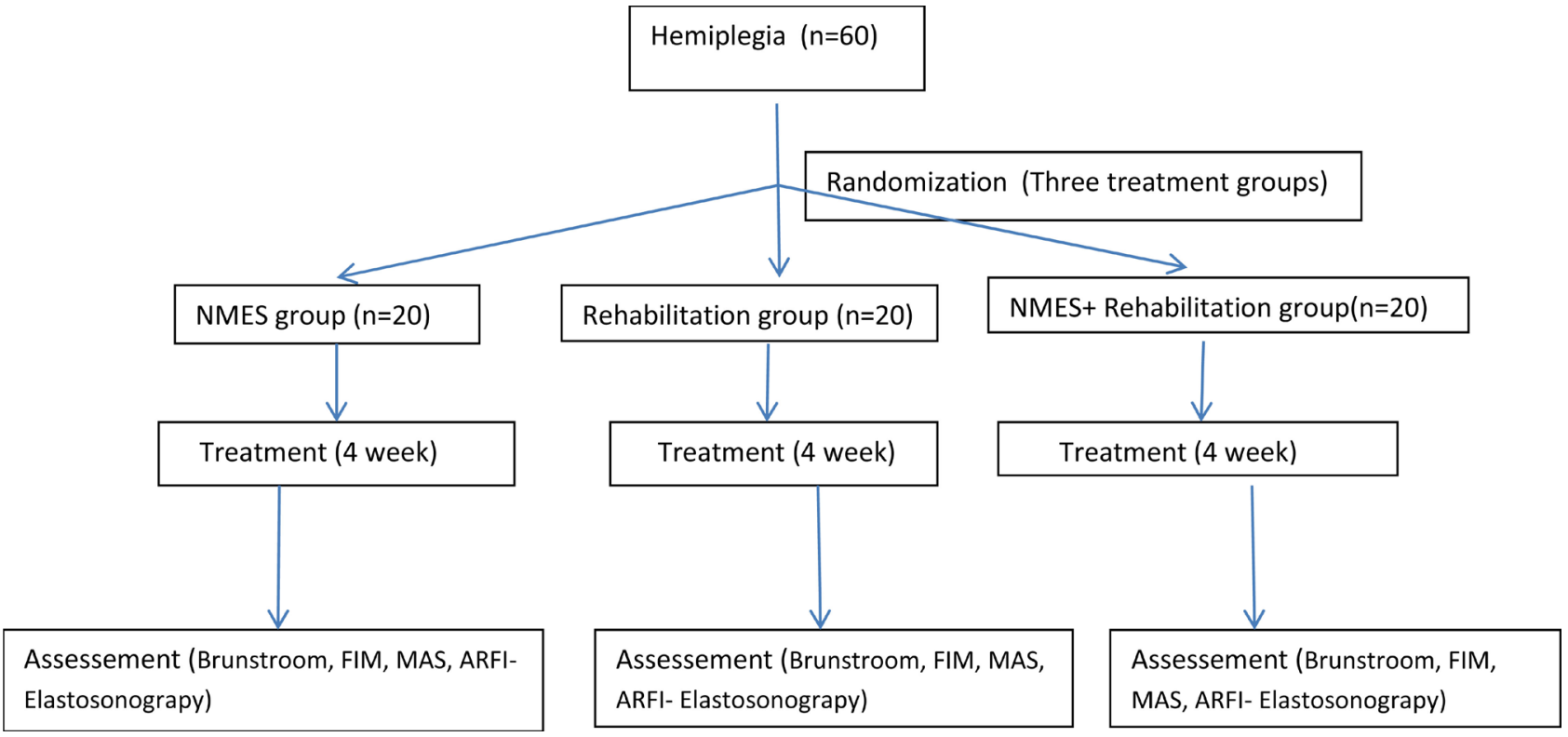

Figure 1. Flow chart of hemiplegia patients. 
compare the continuous variables. The chi-square test was used to compare the distributions of the categorical variables. Duncan multiple comparison tests was used to identify the different groups following the analysis of variance. p-value of $<0.05$ was considered statistically significant. In addition to, descriptive statistics for the studied variables (characteristics) were presented as count and percent.

\section{Results}

Of the 60 subjects, 28 were female $(46.7 \%)$ and 32 (53.3\%) were males, with an average age of $58.42 \pm 9.03$ years. Socio-demographic characteristics of the groups are shown in Table 1.

There was no significant difference between the groups in terms of the FIM scores. There was a significant difference between the upper and lower limbs after the treatment in terms of Brunstroom staging In terms of MAS, there was a significant difference in lower extremity only after treatment (Table 2). There

Table 1. Socio-demographic characteristics of the groups.

\begin{tabular}{|c|c|c|c|c|}
\hline & $\begin{array}{l}\text { NMES group } \\
\quad(\mathrm{n}=20)\end{array}$ & $\begin{array}{l}\text { Rehabilitation } \\
\text { group } \\
(\mathrm{n}=20)\end{array}$ & $\begin{array}{c}\text { NMES + } \\
\text { Rehabilitation } \\
\text { group }(n=20)\end{array}$ & $\mathrm{p}$ \\
\hline Age (year) & $59.1 \pm 8.49$ & $59.15 \pm 10.98$ & $57.0 \pm 7.57$ & 0.699 \\
\hline Gender (F/M) & $11 / 9$ & $9 / 11$ & $8 / 12$ & 0.626 \\
\hline Dominant side $(\mathrm{R} / \mathrm{L})$ & $19 / 1$ & $18 / 2$ & $18 / 2$ & 0.804 \\
\hline Side of involvement $(\mathrm{R} / \mathrm{L})$ & $7 / 13$ & $6 / 14$ & $7 / 13$ & 1.001 \\
\hline Duration of symptoms (month) & $1.97 \pm 0.91$ & $2.05 \pm 0.93$ & $1.90 \pm 0.89$ & 0.874 \\
\hline Body mass index, $\mathrm{kg} / \mathrm{m}^{2}$ & $26.2 \pm 3.7$ & $25.8 \pm 3.9$ & $26.4 \pm 2.1$ & 0.991 \\
\hline \multicolumn{5}{|l|}{ Educational level } \\
\hline No education & $6(30 \%)$ & $8(40 \%)$ & $5(25 \%)$ & \multirow{3}{*}{0.704} \\
\hline Elementary school & $7(35 \%)$ & $8(40 \%)$ & $10(50 \%)$ & \\
\hline Middle school & $7(35 \%)$ & $4(20 \%)$ & $5(25 \%)$ & \\
\hline \multicolumn{5}{|l|}{ Type of stroke } \\
\hline Infarct & $14(70 \%)$ & $13(65 \%)$ & $14(70 \%)$ & \multirow[t]{2}{*}{0.926} \\
\hline Hemorrhage & $6(30 \%)$ & $7(35 \%)$ & $6(30 \%)$ & \\
\hline \multicolumn{5}{|l|}{ Disease } \\
\hline Hypertension & 12 & 12 & 11 & \multirow{5}{*}{0.887} \\
\hline Diabetes Mellitus & 6 & 5 & 6 & \\
\hline COLD & 2 & 3 & 3 & \\
\hline Rheumatic disease & 1 & 1 & - & \\
\hline Other & 4 & 5 & 4 & \\
\hline Smoking & 9 & 12 & 10 & 0.614 \\
\hline Alcohol consume & 2 & 2 & 1 & 0.918 \\
\hline Stroke history & 1 & - & - & \\
\hline
\end{tabular}

NMES, Neuro muscular electro stimulation, F, Female, M, Male, R, Right, L, Left, SD, Standard deviation; COLD: chronic obstrictif lung Disease, ${ }^{*} \mathrm{p}<0.05$. 
was no difference in the sonographic findings of both biceps and gastrocnemius muscles in terms of affected/unaffected sides among the groups (Table 3 ).

When compared to the affected/unaffected side, before and after treatment, there was a significant difference in the measurements in both the medial gastrocnemius and the lateral gastrocnemius in all three groups (Table 4).

Table 2. FIM, Brunstroom and MAS characteristics of the groups.

\begin{tabular}{cccccc}
\hline & & $\begin{array}{c}\text { NMES Group } \\
(\mathbf{n}=20)\end{array}$ & $\begin{array}{c}\text { Rehabilitation group } \\
(\mathbf{n}=20)\end{array}$ & $\begin{array}{c}\text { NMES + Rehabilitation } \\
\text { Group }(\mathbf{n}=20)\end{array}$ & p \\
\hline \multirow{2}{*}{ FIM } & BT & $56.40 \pm 14.96$ & $54.50 \pm 15.40$ & $57.75 \pm 15.09$ & 0.794 \\
& PT & $65.90 \pm 13.08$ & $64.75 \pm 14.20$ & $65.15 \pm 20.40$ & 0.974 \\
& Upper-BT & $2.15 \pm 0.87$ & $2.20 \pm 0.76$ & $2.25 \pm 0.91$ & 0.934 \\
B-Stroom & Lower-BT & $2.20 \pm 1.05$ & $2.30 \pm 0.97$ & $2.15 \pm 0.81$ & 0.88 \\
& Hand-BT & $2.10 \pm 0.96$ & $2.70 \pm 0.97$ & $2.10 \pm 1.02$ & 0.095 \\
& Upper-PT & $1.40 \pm 0.59$ & $2.60 \pm 1.31$ & $3.65 \pm 0.98$ & 0.001 \\
& Lower-PT & $2.30 \pm 0.92$ & $1.30 \pm 0.57$ & $2.45 \pm 1.31$ & 0.001 \\
& Hand-PT & $2.20 \pm 0.83$ & $1.5 \pm 0.68$ & $2.90 \pm 0.96$ & 0.001 \\
\multirow{2}{*}{ MAS } & Upper-BT & $1.10 \pm 0.78$ & $1.90 \pm 1.11$ & $1.10 \pm 0.85$ & 0.011 \\
& Lower-BT & $1.30 \pm 0.92$ & $1.80 \pm 1.10$ & $1.20 \pm 0.83$ & 0.116 \\
& Upper-PT & $0.85 \pm 0.74$ & $1.55 \pm 0.75$ & $0.90 \pm 0.55$ & 0.003 \\
& Lower-PT & $0.45 \pm 0.60$ & $1.35 \pm 0.58$ & $0.75 \pm 0.63$ & 0.001 \\
\hline
\end{tabular}

NMES, Neuro muscular electro stimulation, FIM, Functional Independent Measurement, B-stroom, Brunstroom scale, MAS, Modified Ashworth Scale, BT; Before treatment, PT;Post treatment, SD, Standard deviation, ${ }^{*} \mathrm{p}<0.05$.

Table 3. Comparison of sonoelastographic findings of groups.

\begin{tabular}{|c|c|c|c|c|c|c|}
\hline & & & $\begin{array}{l}\text { NMES Group } \\
\quad(\mathrm{n}=20)\end{array}$ & $\begin{array}{l}\text { Rehabilitation group } \\
\qquad(\mathrm{n}=20)\end{array}$ & $\begin{array}{l}\text { NMES + Rehabilitation } \\
\text { Group }(n=20)\end{array}$ & $\mathrm{p}$ \\
\hline \multirow[t]{4}{*}{ Medial gastocnemius } & Affected side & Elasticity index & $2.59 \pm 0.62$ & $2.40 \pm 0.68$ & $2.42 \pm 0.72$ & 0.641 \\
\hline & & Thickness & $11.63 \pm 2.93$ & $12.13 \pm 2.72$ & $12.86 \pm 2.84$ & 0.392 \\
\hline & Unaffected side & Elasticity index & $2.37 \pm 0.67$ & $1.96 \pm 0.60$ & $2.38 \pm 0.71$ & 0.076 \\
\hline & & Thickness & $13.19 \pm 2.20$ & $12.37 \pm 2.02$ & $12.15 \pm 2.35$ & 0.299 \\
\hline \multirow[t]{4}{*}{ lateral gastrocnemius } & Affected side & Elasticity index & $2.48 \pm 0.69$ & $2.43 \pm 0.61$ & $2.54 \pm 0.63$ & 0.875 \\
\hline & & Thickness & $11.25 \pm 2.41$ & $11.36 \pm 1.85$ & $12.28 \pm 2.23$ & 0.268 \\
\hline & Unaffected side & Elasticity index & $2.38 \pm 0.64$ & $2.41 \pm 0.61$ & $2.51 \pm 0.76$ & 0.812 \\
\hline & & Thickness & $12.41 \pm 2.27$ & $12.00 \pm 2.28$ & $12.00 \pm 2.73$ & 0.828 \\
\hline \multirow[t]{4}{*}{ Biceps muscle } & Affected side & Elasticity index & $3.06 \pm 0.90$ & $3.02 \pm 0.73$ & $3.05 \pm 0.76$ & 0.988 \\
\hline & & Thickness & $19.94 \pm 1.28$ & $18.93 \pm 2.13$ & $19.34 \pm 1.53$ & 0.174 \\
\hline & Unaffected side & Elasticity index & $2.84 \pm 1.08$ & $2.79 \pm 0.81$ & $2.82 \pm 0.95$ & 0.989 \\
\hline & & Thickness & $19.91 \pm 1.12$ & $18.19 \pm 1.86$ & $18.37 \pm 1.92$ & 0.003 \\
\hline
\end{tabular}

NMES, Neuro musculer electro stimulation, SD, Standard deviation; ${ }^{*} \mathrm{p}<0.05$. 
Table 4. Comparison of gastrocnemius sonoelastographic findings of groups.

\begin{tabular}{|c|c|c|c|c|c|c|c|c|c|c|c|}
\hline & & \multicolumn{5}{|c|}{ Medial gastrocnemius } & \multicolumn{5}{|c|}{ Lateral gastrocnemius } \\
\hline & & \multicolumn{2}{|c|}{ Affected side } & \multicolumn{2}{|c|}{ Unaffected side } & \multirow[b]{2}{*}{$\mathrm{p}$} & \multicolumn{2}{|c|}{ Affected side } & \multicolumn{2}{|c|}{ Unaffected side } & \multirow[b]{2}{*}{$\mathrm{p}$} \\
\hline & & $\begin{array}{c}\text { Elasticity } \\
\text { index }\end{array}$ & Thickness & $\begin{array}{c}\text { Elasticity } \\
\text { index }\end{array}$ & Thickness & & $\begin{array}{c}\text { Elasticity } \\
\text { index }\end{array}$ & Thickness & $\begin{array}{c}\text { Elasticity } \\
\text { index }\end{array}$ & Thickness & \\
\hline \multirow{2}{*}{$\begin{array}{l}\text { NMES } \\
(=20)\end{array}$} & $\mathrm{BT}$ & $2.59 \pm 0.62$ & $11.63 \pm 2.93$ & $2.37 \pm 0.67$ & $13.19 \pm 2.20$ & \multirow{2}{*}{0.001} & $2.48 \pm 0.69$ & $11.25 \pm 2.41$ & $2.38 \pm 0.64$ & $12.41 \pm 2.27$ & \multirow{2}{*}{0.001} \\
\hline & PT & $2.92 \pm 0.61$ & $12.58 \pm 2.88$ & $2.83 \pm 0.66$ & $14.29 \pm 2.42$ & & $3.07 \pm 0.69$ & $12.23 \pm 2.18$ & $2.81 \pm .71$ & $13.26 \pm 2.19$ & \\
\hline \multirow{2}{*}{$\begin{array}{l}\text { Rehabilitation } \\
\quad(\mathrm{n}=20)\end{array}$} & $\mathrm{BT}$ & $2.40 \pm 0.68$ & $12.13 \pm 2.72$ & $1.96 \pm 0.60$ & $12.37 \pm 2.02$ & \multirow{2}{*}{0.001} & $2.43 \pm 0.61$ & $11.36 \pm 1.85$ & $2.41 \pm 0.61$ & $12.00 \pm 2.28$ & \multirow{2}{*}{0.001} \\
\hline & PT & $2.73 \pm 0.67$ & $12.94 \pm 2.71$ & $2.50 \pm 0.62$ & $13.88 \pm 2.43$ & & $3.14 \pm 0.69$ & $12.41 \pm 1.63$ & $3.04 \pm 0.87$ & $13.17 \pm 2.65$ & \\
\hline \multirow{2}{*}{$\begin{array}{c}\text { NMES + } \\
\text { Rehabilitation } \\
(\mathrm{n}=20)\end{array}$} & $\mathrm{BT}$ & $2.42 \pm 0.72$ & $12.86 \pm 2.84$ & $2.38 \pm 0.71$ & $12.15 \pm 2.35$ & \multirow[b]{2}{*}{0.001} & $2.54 \pm 0.63$ & $12.28 \pm 2.23$ & $2.51 \pm 0.76$ & $12.00 \pm 2.73$ & \multirow[b]{2}{*}{0.001} \\
\hline & $\mathrm{PT}$ & $2.94 \pm 0.74$ & $13.85 \pm 2.93$ & $2.77 \pm 0.68$ & $13.37 \pm 2.75$ & & $3.14 \pm 0.64$ & $13.24 \pm 2.08$ & $2.98 \pm 0.88$ & $13.04 \pm 2.51$ & \\
\hline
\end{tabular}

NMES, Neuro musculer electro stimulation, BT, before treatment, PT, Post-treatment, SD, Standard deviation; ${ }^{*} \mathrm{p}<0.05$.

Table 5. Comparison of biceps muscle sonoelastographic findings of groups.

\begin{tabular}{|c|c|c|c|c|c|c|c|}
\hline & & \multicolumn{6}{|c|}{ Biceps muscle } \\
\hline & & \multicolumn{3}{|c|}{ Affected side } & \multicolumn{3}{|c|}{ Unaffected side } \\
\hline & & Elasticity index & Thickness & $\mathrm{p}$ & Elasticity index & Thickness & $\mathrm{p}$ \\
\hline \multirow{2}{*}{$\operatorname{NMES}(=20)$} & $\mathrm{BT}$ & $3.06 \pm 0.90$ & $19.94 \pm 1.28$ & \multirow{2}{*}{0.001} & $2.84 \pm 1.08$ & $19.91 \pm 1.12$ & \multirow{2}{*}{0.001} \\
\hline & $\mathrm{PT}$ & $3.42 \pm 0.79$ & $20.54 \pm 1.27$ & & $3.11 \pm 1.0$ & $20.54 \pm 1.09$ & \\
\hline \multirow{2}{*}{ Rehabilitation $(\mathrm{n}=20)$} & BT & $3.02 \pm 0.73$ & $18.93 \pm 2.13$ & \multirow{2}{*}{0.001} & $2.79 \pm 0.81$ & $18.19 \pm 1.86$ & \multirow{2}{*}{0.001} \\
\hline & $\mathrm{PT}$ & $3.25 \pm 0.69$ & $19.28 \pm 2.15$ & & $2.96 \pm 0.79$ & $18.63 \pm 1.95$ & \\
\hline \multirow{2}{*}{ NMES + Rehabilitation $(\mathrm{n}=20)$} & BT & $3.05 \pm 0.76$ & $19.34 \pm 1.53$ & \multirow{2}{*}{0.001} & $2.82 \pm 0.95$ & $18.37 \pm 1.92$ & \multirow{2}{*}{0.001} \\
\hline & PT & $3.35 \pm 0.72$ & $19.74 \pm 1.55$ & & $3.00 \pm 0.93$ & $18.83 \pm 1.94$ & \\
\hline
\end{tabular}

NMES, Neuro muscular electro stimulation, BT, before treatment, PT, Post-treatment, SD, Standard deviation; ${ }^{*} \mathrm{p}<0.05$.

There was a significant difference in the measurements of the biceps in the three groups compared to the affected/unaffected sides, before and after the treatment (Table 5).

\section{Discussion}

Our aim in this study was to evaluate the thickness and elasticity index of the affected/unaffected limb muscles in hemiplegic patients before and after treatment. The major findings of the present study were that 1) significant difference in before-treatment and after-treatment elastosonographic index and thickness in all three groups, 2) only a weak correlation was found in the lower extremity in terms of the mas scores, 3) good recovery was observed in NMES + Rehabilitation group while NMES or Rehabilitation groups had less recovery, and 4) neuromuscular electrical stimulation, unilateral/bilateral exercises have been shown to provide similar neuromuscular responses when performed at the same relative load. To the best of our knowledge, in the literature, no other study has attempted to quantify the degree of muscle hardness in hemiplegia with biceps 
and GCM muscle using ARFI.

One of the most important problems in monitoring in Hemiplegia is the lack of suitable measuring tools for the assessment of the efficiency of diagnosis and treatment methods for muscle tonus in clinical practice. Clinical measurements can give some information (like MAS, Tardieu); however, these are subjective.

Evaluation of therapeutic efficacy should be based not only on the clinical findings but also on imaging findings. ARFI elastography is a new technique that can measure muscle tonus noninvasively and objectively, and it can indirectly inform us about muscle tonus and can help us to evaluate the efficiency of the treatments in these patients. Kesikburun et al. [23]. found a weak correlation in the study that elastography assessed the effect of spasticity on hemiplegia patients. Know et al. [27]. similar results found in the study of medial gastrocnemius spasticity in CP. Also, Yaşar et al. [24]. found high stiffness grades in spastic muscles in sonoelastographic parameters in their studies using MAS and Tardieu scales. Cho et al. assessed the spastic extremity (GCM and biceps) muscle of spinal cord injury (SCI) patients with the ARFI technique and found differences between spastic SCI patients, nonspastic SCI patients, and normal controls [30]. When we compared the results of the study, our results were similar.

In a study conducted with spastic biceps brachii muscles of stroke patients [31], Askin et al. showed that strain index values decreased significantly after botulinum toxin-A injection. In another study [32], when the biceps brachii shear wave speed was compared between the nonparetic and paretic sides, The shear wave speed was $69.5 \%$ greater in paretic muscle than nonparetic muscle (Cs $=3.67 \pm 1.28 \mathrm{~m} / \mathrm{sec}$ vs. $2.23 \pm 0.40 \mathrm{~m} / \mathrm{sec} ; \mathrm{P}<0.001)$.

This difference can be due to a number of reasons; 1) muscle thickness is known to be influenced by many factors including age, gender, morphology. 2) muscles are subject to anisotropy, so there may be different results. 3) Also, this difference may have been caused by muscle weakness and inactivity and/or nutritional disorders secondary to hemiplegia in these patients.

Consequently, these changes appear to result in increased accumulation of collagen tissue content and loss of skeletal muscle fibers.

Our study had a few limitations. Firstly, the number of subjects was small so statistical power was low. Secondly, it was not possible to examine the relationship between the change in hardness and elasticity of the muscles and disease duration because patients in our study were diagnosed within 6 months. Finally, the absence of a control group with no hemiplegia was the main shortcoming of this study; to overcome it in this study a unaffected side was taken as the control group.

\section{Conclusion}

The role of elastography in evaluating hemiplegic patients is not clear when considering the difficulty in standardization. Further research with larger numbers of patients for longer periods is needed to clarify the relationship between the 
muscle hardness and degree of spasticity.

\section{Conflicts of Interest}

The authors declare no conflicts of interest regarding the publication of this paper.

\section{References}

[1] Idowu, B.M., Ayoola, O.O., Adetiloye, V.A. and Komolafe, M.A. (2017) Sonographic Evaluation of Structural Changes in Post-Stroke Hemiplegic Shoulders. Polish Journal of Radiology, 3, 141-148. https://doi.org/10.12659/PJR.899684

[2] Li, H., Zhao, G,, Zhou, Y., Chen, X., Ji, Z. and Wang, L. (2014) Relationship of EMG/SMG Features and Muscle Strength Level: An Exploratory Study on Tibialis Anterior Muscles during Plantar-Flexion among Hemiplegia Patients. Biomedical Engineering Online, 6, 13-15. https://doi.org/10.1186/1475-925X-13-5

[3] Vinstrupa, J., Calatayuda, J., Jakobsena, M.D., Sundstrupa, E., Jaya, K., Brandta, M., Zeeman, P., Jorgensen, J.R. and Andersen, L.L. (2017) Electromyographic Comparison of Conventional Machine Strength Training versus Bodyweight Exercises in Patients with Chronic Stroke. Topics in Stroke Rehabilitation, 4, 242-249. https://doi.org/10.1080/10749357.2016.1274466

[4] Billinger, S.A., Arena, R., Bernhardt, J., Eng, J.J., Franklin, B.A., Johnson, C.M., MacKay-Lyons, M., Macko, R.F., Mead, G.E., Roth, E.J. and Shaughnessy, M. (2014) Physical Activity and Exercise Recommendations for Stroke Survivors: A Statement for Healthcare Professionals from the American Heart Association/American Stroke Association. Stroke, 8, 2532-2553. https://doi.org/10.1161/STR.0000000000000022

[5] Muro-Culebras, A. and Cuesta-Vargas, A.I. (2013) Sono-Myography and Sono-Myoelastography of the Tender Points of Women with fibromyalgia. Ultrasound in Medicine \& Biology, 39, 1951-1957.

https://doi.org/10.1016/j.ultrasmedbio.2013.05.001

[6] Lee, S.Y., Park, H.J., Choi, Y.J., Choi, S.H., Kook, S.H., Rho, M.H. and Chung, E.C. (2013) Value of Adding Sonoelastography to Conventional Ultrasound in Patients with Congenital Muscular Torticollis. Pediatric Radiology, 43, 1566-1572. https://doi.org/10.1007/s00247-013-2750-x

[7] Kuo, W.H., Jian, D.W., Wang, T.G. and Wang, Y.C. (2013) Neck Muscle Stiffness Quantified by Sonoelastography Is Correlated with Body Mass Index and Chronic Neck Pain Symptoms. Ultrasound in Medicine \& Biology, 39, 1356-1361. https://doi.org/10.1016/j.ultrasmedbio.2012.11.015

[8] Botar, Jid, C., Vasilescu, D., Damian, L., Dumitriu, D., Ciurea and Dudea, S.M. (2012) Musculoskeletal Sonoelastography. Pictorial Essay. Medical Ultrasonography, 14, 239-245.

[9] Drakonaki, E.E., Allen, G.M. and Wilson, D.J. (2012) Ultrasound Elastography for Musculoskeletal Applications. The British Journal of Radiology, 85, 1435-1445. https://doi.org/10.1259/bjr/93042867

[10] Nightingale, K. (2011) Acoustic Radiation Force Impulse (ARFI) Imaging: A Review. Current Medical Imaging Reviews, 7, 328-339. https://doi.org/10.2174/157340511798038657

[11] Palmeri, M.L., Wang, M.H., Dahl, J.J., Frinkley, K.D. and Nightingale, K.R. (2008) Quantifying Hepatic Shear Modulus in Vivo Using Acoustic Radiation Force. UI- 
trasound in Medicine \& Biology, 34, 546-558.

https://doi.org/10.1016/j.ultrasmedbio.2007.10.009

[12] Meng, W., Zhang, G., Wu, C., Wu, G., Song, Y. and Lu, Z. (2011) Preliminary Results of Acoustic Radiation Force Impulse (ARFI) Ultrasound Imaging of Breast Lesions. Ultrasound in Medicine \& Biology, 37, 1436-1443.

https://doi.org/10.1016/j.ultrasmedbio.2011.05.022

[13] Stock, K.F., Klein, B.S., Vo, Cong, M.T., Sarkar, O., Romisch, M., Regenbogen, C., Büttner, M., Schuster, T., Matevossian, E., Amann, K., Clevert, D.A., Heemann, U. and Küchle, C. (2010) ARFI-Based Tissue Elasticity Quantification in Comparison to Histology for the Diagnosis of Renal Transplant Fibrosis. Clinical Hemorheology and Microcirculation, 46, 139-148.

[14] Bota, S., Sporea, I., Sirli, R., Popescu, A., Danila, M., Sendroiu, M. and Focşa, M. (2010) Spleen Assessment by Acoustic Radiation Force Impulse Elastography (ARFI) for Prediction of Liver Cirrhosis and Portal Hypertension. Medical Ultrasonography, 12, 213-217.

[15] Zhai, L., Polascik, T.J., Foo, W.C., Rosenzweig, S., Palmeri, M.L., Madden, J. and Nightingale, K.R. (2012) Acoustic Radiation Force Impulse Imaging of Human Prostates: Initial in Vivo Demonstration. Ultrasound in Medicine \& Biology, 38, 50-61. https://doi.org/10.1016/j.ultrasmedbio.2011.10.002

[16] D’Onofrio, M., Gallotti, A., Martone, E. and Pozzi Mucelli, R. (2009) Solid Appearance of Pancreatic Serous Cystadenoma Diagnosed as Cystic at Ultrasound Acoustic Radiation Force Impulse Imaging. Journal of the Pancreas, 10, 543-546.

[17] D’Anastasi, M., Schneevoigt, B.S., Trottmann, M., Crispin, A., Stief, C., Reiser, M.F. and Clevert, D.A. (2011) Acoustic Radiation Force Impulse Imaging of the Testes: A Preliminary Experience. Clinical Hemorheology and Microcirculation, 49, 105-114.

[18] Friedrich-Rust, M., Romenski, O., Meyer, G., Dauth, N., Holzer, K., Grunwald, F., Kriener, S., Herrmann, E., Zeuzem, S. and Bojunga, J. (2012) Acoustic Radiation Force Impulse-Imaging for the Evaluation of the Thyroid Gland: A Limited Patient Feasibility Study. Ultrasonics, 52, 69-74. https://doi.org/10.1016/j.ultras.2011.06.012

[19] Kot, B.C., Zhang, Z.J., Lee, A.W., Leung, V.Y. and Fu, S.N. (2012) Elastic Modulus of Muscle and Tendon with Shear Wave Ultrasound Elastography: Variations with Different Technical Settings. PLoS ONE, 7, e44348.

https://www.ncbi.nlm.nih.gov/pmc/articles/PMC3432131/ https://doi.org/10.1371/journal.pone.0044348

[20] Bouillard, K., Nordez, A., Hodges, P.W., Cornu, C. and Hug, F. (2012) Evidence of Changes in Load Sharing Isometric Elbow Flexion with Ramped Torque. Journal of Biomechanics, 45, 1424-1429. https://doi.org/10.1016/j.jbiomech.2012.02.020

[21] Yavuz, A., Bora, A., Bulut, M.D., Batur, A., Milanlioglu, A., Göya, C. and Andic, C. (2015) Acoustic Radiation Force Impulse (ARFI) Elastography Quantification of Muscle Stiffness over a Course of Gradual Isometric Contractions: A Preliminary Study. Medical Ultrasonography, 17, 49-57. https://doi.org/10.11152/mu.2013.2066.171.yvz

[22] Lacourpaille, L., Hug, F., Bouillard, K., Hogrel, J.Y. and Nordez, A. (2012) Supersonic Shear Imaging Provides a Reliable Measurement of Resting Muscle Shear Elastic Modulus. Physiological Measurement, 3, 19-28.

https://doi.org/10.1088/0967-3334/33/3/N19

[23] Kesikburun, S., Yaşar, E., Adıgüzel, E., Güzelküçük, Ü., Alaca, R. and Tan, A.K. (2015) Assessment of Spasticity With Sonoelastography Following Stroke: A Feasibility Study. $P M \&$ \& 7, 1254-1260. https://doi.org/10.1016/j.pmrj.2015.05.019 
[24] Yaşar, E., Adigüzel, E., Kesikburun, S., Yenihayat, I., Yilmaz, B., Alaca, R. and Tan, A.K. (2016) Assessment of Forearm Muscle Spasticity with Sonoelastography in Patients with Stroke. British Journal of Radiology, 89, 20160603.

https://www.ncbi.nlm.nih.gov/pmc/articles/PMC5604927/pdf/bjr.20160603.pdf https://doi.org/10.1259/bjr.20160603

[25] Chernak, L.A., DeWall, R.J., Lee, K.S. and Thelen, D.G. (2013) Length and Activation Dependent Variations in Muscle Shear Wave Speed. Physiological Measurement, 34, 713-721. https://doi.org/10.1088/0967-3334/34/6/713

[26] Basford, J.R., Jenkyn, T.R., An, K.-N., Ehman, R.L., Heers, G. and Kaufman, K.R. (2002) Evaluation of Healthy and Diseased Muscle with Magnetic Resonance Elastography. Archives of Physical Medicine and Rehabilitation, 83, 1530-1536. https://doi.org/10.1053/apmr.2002.35472

[27] Kwon, D.R., Park, G.Y., Lee, S. and Chung, I. (2012) Spastic Cerebral Palsy in Children: Dynamic Sonoelastographic Findings of Medial Gastrocnemius. Radiology, 263, 794-801. https://doi.org/10.1148/radiol.12102478

[28] Lee, S.S., Spear, S. and Rymer, W.Z. (2015) Quantifying Changes in Material Properties of Stroke-Impaired Muscle. Clinical Biomechanics, 30, 269-275.

https://doi.org/10.1016/j.clinbiomech.2015.01.004

[29] Kucukdeveci, A.A., Yavuzer, G., Elhan, A.H., Sonel, B. and Tennant, A. (2001) Adaptation of the Functional Independence Measure for Use in Turkey. Clinical Rehabilitation, 15, 311-319. https://doi.org/10.1191/026921501676877265

[30] Cho, K.H. and Nam, J.H. (2015) Evaluation of Stiffness of the Spastic Lower Extremity Muscles in Early Spinal Cord Injury by Acoustic Radiation Force Impulse Imaging. Annals of Rehabilitation Medicine, 39, 393-400. https://doi.org/10.5535/arm.2015.39.3.393

[31] Askın, A., Kalaycı, O.T., Bayram, K.B., Tosun, A., Demirdal, Ü.S., Atar, E. and İnci, M.F. (2016) Strain Sonoelastographic Evaluation of Biceps Muscle Intrinsic Stiffness after Botulinum Toxin-A Injection. Topics in Stroke Rehabilitation, 23, 1-6.

[32] Lee, S.S., Spear, S. and Rymer, W.Z. (2015) Quantifying Changes in Material Properties of Stroke-Impaired Muscle. Clinical Biomechanics, 30, 269-275.

https://doi.org/10.1016/j.clinbiomech.2015.01.004 